\title{
COMPRESSION FAILURE MECHANISMS OF UNI-PLY COMPOSITE PLATES WITH A CIRCULAR CUTOUT
}

\author{
A. R. Khamseh* and A. M. Waas ${ }^{\dagger}$ \\ Dept. of Aerospace Engineering, Univ. of Michigan, Ann Arbor, MI 48109-2140
}

February 1, 1992

\begin{abstract}
The paper discusses the experimental and finite element investigation into the failure mechanisms of uniply graphite-epoxy composite plates with circular holes loaded in uniaxial compression. The effect of hole size on the failure mode is established. Test specimens composed of a single layer of uniply graphite-epoxy sandwiched between two layers of transparent polyetherimide plastic were designed and produced. This unique stacking geometry enabled the investigators to carry out a nondestructive evaluation of the failure mechanisms associated with the uniply. A wide range of hole sizes was tested in order to document the dependance of failure modes to specimen geometry. The experimental work made use of real time holographic interferometry and photomicrography to study the initiation of failure in the test specimens.
\end{abstract}

A Finite Element Analysis (FEA) was carried out for those specimens which exhibited in-plane failure initiated at the edge of the hole. The analysis modelled the graphite-epoxy uniply in an attempt to reproduce the results obtained experimentally.

Experimental results revealed failure initiation to occur at the edge of the hole, in the form of fiber microbuckling/ kinking, followed by delamination, for specimens with hole sizes varying from the largest down to a cutoff hole size. Below this range, failure either initiated at the outer free edges, in the forms of cracks, or was in the form of global (total) delamination. The FEA results agreed very well with the buckled mode shapes from the experimental results, although the estimated buckling loads were larger than those obtained

\footnotetext{
*Graduate Research Assistant, Student Member AIAA

${ }^{\dagger}$ Asst. Professor of Aerospace Engineering, Member AIAA. Copyright c 1992 by Anthony M. Waas. Published by the American Institute of Aeronautics and Astronautics, Inc. with permission.
}

from experiments, probably due to imperfections in loading and material composition in the experiments. The trends for buckling modes and loads agree quite well for the two phases, revealing the inverse behaviour between buckling load and hole size.

\section{Introduction}

In recent years, an increasing proportion of fiber laminated composites are finding application particularly in the aerospace industry. In this field it is desirable to maximize the stiffness/weight ratio while maintaining the necessary strength requirements in selecting a material for a particular application. The reason for this desire is that much of the structure of an aircraft is in compression, and compression carrying members are usually plates, which are thin in comparison to their inplane dimensions. The requirements of high strength/weight and/or high stiffness/weight ratios are seldom compatible in isotropic materials, and it is this facet of design that composites are able to exploit. In addition to the aforementioned advantage of high strength/weight ratio is the freedom to tailor the directional dependance of stiffness in composites over 'traditional' materials like metals. These facts are demonstrated in the texts by Mallick [1] and McCrum et. al [2], where tables showing property comparisons are given.

Successful implementation of graphite-epoxy in secondary structures on commercial and military aircraft[1] has made the use of such composites in aircraft structures very attractive, but at the same time test results which have shown the compression strength of heavily loaded wing and fuselage skins to be reduced by local discontinuities such as holes [3] have warranted the need for an in-depth examination of the failure mechanisms involved with graphite-epoxy composites with 
cutouts under compression. The problem of identification and verification of the failure mechanisms of typical unidirectional (parallel) continous fiber plies in the presence of stress gradients generated by a circular cutout and subjected to uniaxial compressive loading is of considerable importance because such plies are the fundamental building blocks in the construction of fibrous composite laminated plates

An experimental investigation was conducted to isolate and study the failure mechanisms associated with compressive-loaded uniply $\left(0^{0}\right)$ graphite-epoxy square plates with a centrally located circular hole; Full details and results of that investigation are reported elsewhere [4]. For the sake of completeness some repetition here is unavoidable. The compressive behavior of the plates is discussed. The effect of hole diameter on the compressive strength and failure mode of the graphiteepoxy uniply plates is reported and quantified. The failure mechanisms for the laminates are dicussed. The sequence of events that occured in the vicinity of the hole during failure was identified and provided information into the mechanisms associated with failure. A closed-form anisotropic plate analysis formulation [5] was used to determine the stress distribution around the hole.

A Finite Element Analysis (FEA) incorporating classical lamination theory was carried out utilizing the measured material properties and geometries, in order to gain insight into the in-plane failure mechanisms evident in the experimental observations.

\section{Previous Research}

Various modes of compressive failure of the lamina have been suggested for predicting failure mechanisms in composites under compressive loading, amongst which are: fiber failure, matrix failure, fiber/matrix debonding, and fiber splitting. In several previous articles [6-17], researchers had identified fiber buckling/kinking as a viable mode of compressive failure in fibrous composite laminated plates. These researchers all experimentally investigated the problem of compressive failure of laminated plates that contained a circular cutout. In most cases, the plate dimensions were several times the diameter of the cutout, so that the effects of the cutout would not interfere with the load distribution details at the edge of the plate. When the laminated plate contained $0^{\circ}$ plies the fundamental mechanism of failure initiation was found $[6,11,12,15-17]$ to be fiber buckling/kinking occuring close to the net section and adjacent to the cutout. Unfortunately, no complete examination of the relationship between hole size and failure mechanism associated with composite plates under compressive loading has been carried out to this date. It was the purpose of this investigation to address this issue.

\section{Test Specimens}

Specially designed 'model' composite plates made of sandwiching a unidirectional graphite-epoxy ply between two transparent, isotropic polyetherimide (commercial name: ULTEM) thermoplastic sheets were used (see Fig. 1). The transparent property of this commercially available thermoplastic allowed for an in-situ visual identification of failure initiation and propagation, effectively acting as a 'window' for observation of the compressive response of the graphite-epoxy ply without the need to deply the laminate. The graphite-epoxy tested in this investigation was a sample of commercially available, high strength, low modulus, continuous, filamentary, unidirectional tape, designation number T2C-190/F155, from Hexcel Corporation. Fiber volume fraction $\left(V_{f}\right)$ was 0.57 for the tape used in the investigation, typical of the material used in industry $[1],[2]$.

Typical engineering material properties for the graphite, epoxy, and the thermoplastic polymer are given in Table 1. The micromechanics approach was used to obtain the effective moduli of the graphiteepoxy lamina. As noted in the work of Waas [18], there are several ways to obtain the effective moduli, depending on the level of sophistication, and inherently the level of accuracy, desired. The one chosen for this investigation was from Tsai and Hahn [19], who proposed the self-consistent model of a concentric cylinder representative volume element for the fiber and matrix. Using the formulae derived by Tsai and Hahn, the effective moduli of the tape were calculated and compared (when possible) with the information given by the manufacturer. Good agreement was found between the two.

Surface strain gage measurements at various locations on the specimen were recorded. From these the critical value of local (i.e. at the hole edge) strain at failure initiation was deduced using an analytical formulation [5] for the stress concentration factors at any point of the specimen, given the material properties of the specimen. This procedure was followed since the finite width of the strain gages (we used strain gages at the hole edge with dimensions ranging from 0.04 in. to 0.10 in. in width) precludes a measurement of strain at the very edge of the hole. The final stacking geometry chosen for the analytical formulation, based on experimental observations, was a 3-ply symmetric (about 
the middle ply) stacking sequence, where the outermost plies were the 0.1335 in. thermoplastic sheets, with the 0.008 in. graphite-epoxy tape in the middle. The stress concentration factor at the hole determined for this geometry was 3.57 . The results obtained were compared to experimental values obtained for some of the material properties for the plates (see Table 2), and agree favorably well.

The laminates were cured under heat and pressure in a compression mold. All specimens were cut into flat square plates $1.68(+/-0.005)$ in. $\times 1.68(+/-0.005)$ in. in planform, and $0.275 \mathrm{in}$. thick. The inplane dimensions of the plate specimens used in the tests described below were chosen to ensure that overall plate buckling would not be responsible for initiation of failure. Uniform, circular holes were drilled into the center of the specimens, with hole diameters ranging from 0.0078 in. to 0.332 in., remaining in a range well suited for infinite plate assumptions (i.e. $\frac{w}{d}>5$, where $d$ is the hole diameter and $w$ is the plate width). Prior to testing each specimen was optically scanned for any possible failure due to machining, such as delamination or the above mentioned fiber pullout at free edges.

The above mentioned precautions were taken to insure a specimen free of any imperfections prior to testing.

\section{Apparatus and Tests}

Test specimens were loaded in uniaxial compression using a 50,000 lbf. capacity hydraulic testing machine. The loaded ends of the specimen were clamped while the two remaining edges were free.

Real time Holographic Interferometry was the optical technique chosen to locate the initial failure point. The interferometric data from this procedure indicate the changes in the out of plane displacement component of the test specimen. These changes are the manifestations of internal damage. One of the advantages of this optical procedure is its ability to isolate failure mechanisms that occur on the micro length scale of the material: the fiber diameter.

A load cell and electrical resistance foil strain gages were used to ubtain a load time history and local surface strain values near the hole as well as in the far field. Fig. 2 shows the location of the back-to-back gages on the test specimens. The load and strain time history were recorded continuously on a computer using commercial data analysis software. Sectioning studies, using an optical microscope, of partly damaged plates provided information into the failure mechanisms.

All specimens were tested by slowly applying a compressive load, at a constant rate of $5000 \mathrm{lbs}$. of force per hour, to simulate a static loading condition. All tests were conducted at room temperature. Thirty Seven specimens were tested, with the results of failure stresses, failure strains, and modes of failure charted against specimen hole sizes in Table 3 . Some specimens were loaded to global failure (by "global failure" we mean the load at which the specimen lost its structural integrity and load bearing capacity completely), while others were only loaded up through the initial inception of localized failure, as viewed by the hologram and recorded by the strain gages (See Table 3 ).

\section{Finite Element Analysis (FEA)}

For the FEA, a mesh was generated (see Fig. 3) for use with the FEA software HKS-ABAQUS, using the SDRC-IDEAS Pre/Post processing software, for the range of hole sizes which exhibited failure initiation along the region adjacent to the hole edge (as identified in the experimental work, see Results and Discussion). Due to the symmetry conditions for specimen loading and geometry about the y-axis (refer to Fig. 3), the region of interest was reduced by one half in the finite element mesh. The mesh models the middle ply of the plate specimen only, i.e. the graphite-epoxy ply sandwiched between the two thick ULTEM outer layers, as the focus of the FEA was to observe the in-plane failure mechanisms associated with the fibrous layer.

All dimensions of the mesh were nondimensionalized with respect to the hole diameter to allow for quick and efficient modifications to the FEA input files for analysis of each hole size. The choice of dimensions was motivated by the experimental findings that revealed the buckling failure to die out well within the boundaries of the area meshed for the FEA. In proceeding with the FEA, we chose to work with a rectangular mesh containing 15,000 elements (quadrilateral plane strain) and 15251 nodes, with two degrees of freedom ( $x, y$-displacements) per node. It should be noted here that since only the mid-ply graphite-epoxy layer of the plate is under finite element investigation, a state of plane strain can be used in the finite element analysis. In the pre-buckling analysis, the homogeneous material properties, obtained from the experimental analysis, were used to determine the stresses and displacements for all the points in a plate with a hole under an uniaxial compressive loading, using plane stress assumptions as described in reference [5]. On the boundaries 
of the mesh, the pre-buckling displacement fields were enforced as boundary values. The analysis was split into two parts; Modes that are symmetric about the $y$ axis, i.e. buckled displacements that satisfy $u(\mathrm{x})=-u(-$ $\mathrm{x})$ and $v(\mathrm{x})=v(-\mathrm{x})$, and antisymmetric buckling modes, i.e. $u(\mathrm{x})=u(-\mathrm{x})$ and $v(\mathrm{x})=-v(-\mathrm{x})$, where $u$ and $v$ are the displacements in the $\mathrm{x}$ and $\mathrm{y}$ directions, respectively. For the symmetric case, the following boundary values were enforced (see Fig. 3): edge $\mathrm{AB}, u=0$, along edges $\mathrm{BC}, \mathrm{CD}$, and DA, $u=u_{p}, v=v_{p}$ (where the subscript $p$ refers to the values for the displacements obtained from the pre-buckling analysis). For the antisymmetric case, the boundary conditions were the same along edges $\mathrm{BC}$, $\mathrm{CD}$, and $\mathrm{DA}$, but along edge $\mathrm{AB}, v=0$.

The FEM solver HKS-ABAQUS was used to determine the buckling load and corresponding mode for the plate. The FEM used a modified Riks method numerical analysis solver to obtain the eigenvalue (which in the analysis corresponded to the critical load) and mode shape. The mesh used simulated the ordering and volume fraction of fiber-matrix layers as taken from specimen geometry used in the experiments. The dimensions of the rectangular mesh region in Fig. 3 are as follows: the length of the region (x-direction) is $150 d_{f}$, the width (y-direction) is $100 d_{f}$ and the thickness is $29 d_{f}$, which corresponds to the thickness of the midply of the plate (see Fig. 3), where $d_{f}$ is the fiber diameter which in our case is $2.756 \mathrm{E}-04$ inches.

\section{Results and Discussion}

The failure mode for the laminates was determined to be by fiber microbuckling/kinking at the hole edge followed by delamination near the failure site, resulting in the propagation of the damage into the interior of the specimen. This failure mode persists for hole sizes beyond a critical size of $0.1040 \mathrm{in}$. (hole diameter/plate width aspect ratio of 0.0619). The transparent nature of the thermoplastic sheet revealed no delamination associated with the failure initiation in several specimens which were loaded to failure by microbuckling and immediately unloaded,. This finding establishes that fiber microbuckling precedes delamination failure; such a conclusion could not be definite, merely hypothetical, with commercially used opaque graphite-epoxy laminates. For hole sizes smaller than $0.1040 \mathrm{in}$. the failure site shifts away from the hole edge and begins at the free lateral edge, or, as in most cases for this hole size range, failure occurs globally (delamination of the thermoplastic/ply interface throughout the specimen) without any microbuckling.
Optical scanning of damaged sections for those specimens that failed by microbuckling revealed three dimensional buckle patterns (see Fig. 4. Note Specimen "D" refers to specimen 37 in Table 3). In effect, the microbuckling process resulted in the $0^{\circ}$ fibers undergoing large rotations both inplane (xy) and out of plane (xz). Of the several samples with the same hole size that had failure initiated at the hole edge, at least one sample was examined. The procedure for sectioning the specimens was to observe out of plane failure at a distance of $2.0(+/-0.05) \mathrm{mm}$ from the edge of the hole, and to observe inplane failure at the hole edge. The results of the sectioning study are tabulated in Table 4, including half buckle wavelength and band numbers (number of microbuckle/kink bands) for both inplane and out of plane failure. The significant point to note here was that the inplane buckle wavelength satisfied $\frac{\lambda}{d_{f}}>>10$, while for out of plane buckling $\frac{\lambda}{d_{f}}<10$, where $\lambda$ is the buckle half wavelength and $d_{f}$ is the fiber diameter. A plot of buckle half-wavelength for inplane and out of plane buckling, where failure initiated at the hole edge, are given in Fig. 5 , where the nondimensionalized parameter $\frac{\lambda}{d}$ is plotted against the hole aspect ratio $\frac{d}{w}$ for both cases. Note that for the out of plane case, the buckled half wavelength used is for the kink pattern which was common in all failures (see, for example, the out of plane kink pattern for the specimen in Fig. 4). From Fig. 5 we see that the inplane buckle wavelength shows a continuous dependance on the hole size to plate width aspect ratio, $\frac{d}{w}$. However, the out of plane buckle wavelength is constant for hole diameters satisfying values of $\frac{d}{w}$ in excess of 0.1 . Furthermore, from Table 4 we see that the number of buckled/kinked wave bands is constant (one) for inplane buckling, but increases from unity to multiple values, as the hole size decreases, for out of plane buckling.

The results obtained establish that when laminates containing $0^{0}$ plies are loaded in compression, the fibers undergo buckling with a long wavelength inplane mode and a short wavelength out of plane (through the thickness) mode. Furthermore, in the presence of a circular cutout, the failure mode is dictated by the ratio $\frac{d}{w}$. If $\frac{d}{w}$ is beyond a certain limiting value $(0.062)$, the fiber microbuckling/kinking is initiated at the hole edge. If the ratio is smaller than the limiting value, the failure shifts away from the hole edge and in most cases leads to global, instead of micro, buckling. Post failure inspection of the latter case failures, i.e. failure initiation away from the hole edge, showed complete tearing of fibers all along the midline of the specimens, indicating the possibility that failure may be due to through the thickness large stresses. 
The critical strain values for all specimens were recorded (from strain gage measurements) and corresponding hole edge strain values were calculated (See Table 3) and are plotted vs. hole aspect ratio (hole diameter/plate width) in Fig. 6. One must take care in interpreting the data from Fig. 6 for failure strains of the specimens, especially for the small hole size specimens, as several of those specimens developed failure initiation at a free edge and were immediately unloaded, prior to complete specimen failure (see Table 2). Thus, strain values for very small hole size specimens may appear to be very low (see, for example, specimens 3 and 4 in Table 2) when compared to neighboring hole size specimens, but the modes of failure were entirely different. A similar plot is provided from specimens that fell in a range above the ratio $\frac{d}{w}<0.062$ in Fig. 7. The failure strains at the hole edge of the plate for specimens which exhibited failure initiation at the hole edge range from 13000 to $27000 \mu$ strain, and there is indication of a downward sloping trend for failure strain to hole size, i.e. the failure strain decreases for increasing hole diameter. The far field stress values corresponding to failure were computed simply as the failure load (the load at which strain gage readings indicate a drop in value) on the specimen (monitored through the load cell, see Fig. 3) divided by the specimen cross sectional area in contact with the loading apparatus. Not unlike the plots for failure strains, the far field failure stress decreases as the hole diameter grows larger [4].

The finite element model has been used to obtain buckling loads and modes for four hole sizes (see Table 5 ). As noted earlier, all four cases fall into the range of experimental results which indicated fiber failure adjacent to the hole as initiation of failure in the plate. The two extremes of the range were tested (for hole diameter to plate width aspect ratios of 0.06 (smallest) and 0.20 (largest)) along with a two intermediate hole aspect ratio of 0.09 and 0.12 . Representative results for the symmetric and antisymmetric modes are shown in Figures 8 and 9, respectively, for the intermediate hole aspect ratio of 0.12 . The results indicate that the buckling mode shape is symmetric, portraying a sinusoidal wave pattern with a decaying amplitude. Maximum amplitude is at the origin of the mesh, the region of highest instability directly adjacent to the hole, with a rapid decay along both axes as one moves away from the edge of the hole top (compare to the experimental results in Fig. 4). The buckling load exhibits an inverse relationship to the hole aspect ratio, as was recorded in the experimental results. Furthermore, the buckling loads and wavelengths show a downward sloping trend with an increase in the hole size, again correlating with experimental data (see Table 5). As can be seen in the same table, the buckled wavelengths from the FEA agree extremely well with experimental results. The FEA gave buckling loads which were higher (by a factor of 2) than the experimental results. A probable explanation for this stems from the assumption of a perfect system in the FEA, i.e. no fiber breaks, no fiber misalignments, ...etc., which experimentally is not possible, thereby overstiffening the structure. Microscopic examinations of the plate midplies revealed an average fiber length range of approximately 50 to $100 d_{f}$, with a gap range of 2 to $10 d_{f}$ in between fibers.

\section{Concluding Remarks}

The focus of this experimental investigation was to identify, verify and quantify the failure mechanisms involved in the compressive loading of model graphiteepoxy composite plates containing $0^{0}$ plies in the presence of stress gradients generated by circular cutouts. Special unidirectional continous fiber plies were designed and tested with varying hole sizes in the center of the plates. It was determined that the type of compressive failure was a function of the hole size. For large hole sizes, where the aspect ratio of hole diameter to plate width $\frac{d}{w}$ exceeds 0.062 , the dominant failure mechanism was fiber buckling/kinking initiated at the hole and traversing into the plate perpendicular to the direction of loading. In previous similar investigations, the opacity of the graphite-epoxy plates used impaired the determination of the specific failure initiation mechanism; microbuckling followed by delamination, or vice-versa. In the present study, use of the transparent thermoplastic sheets have clearly established that fiber microbuckling / kinking at the hole edge precedes delamination for this hole size range. For small hole sizes, $\frac{d}{w}<0.062$, failure initiated away from the hole edge or complete global failure occured. Critical buckle wavelengths at failure have been presented as a function of normalized hole diameter. The experiments reported have identified the parameters which influence the compressive strength of $0^{0}$ plies in laminated composite plates.

A Finite Element Analysis was carried out on the plates used in the experimental work, using the hole aspect ratio parameter to analyze the buckling loads and mode shapes. Results indicate very good agreement between experimental and computational efforts. 


\section{Acknowledgements}

This study was funded by support received from NASA Langley Research Center Grant NAG-1-1040 and from the Rackham Graduate School at the University of Michigan. The authors are appreciative of this support. The encouragement of Dr. M. J. Shuart, NASA Langley, is gratefully acknowledged. The graphite-epoxy tape material and ULTEM thermoplastic sheets were furnished by Prof. A. F. Yee, Materials Science Department, University of Michigan. The authors thank Prof. Yee and research assistant Ruth Amundson for their generosity.

\section{References}

1. Mallick, P.K., 1988, "Fiber Reinforced Composites: Materials, Manufacturing, and Design", Marcel-Dekker Inc..

2. McCrum, N.G., Buckley, C.P., Bucknall, C.B., 1988, "Principles of Polymer Engineering", Oxford University Press.

3. Starnes, J., Rhodes, M.D., and Williams, J.G., 1979, "Effect of Impact Damage and Holes on the Compressive Strength of a Graphite/Epoxy Laminate", Nondestructive Evaluation and Flaw Criticality for Composite Materials, edited by R. B. Pipes, ASTM STP 696, pp. 145-171.

4. Khamseh, A.R., and Waas, A.M., 1992, "Failure Mechanisms of Uniply Composite Plates with a Circular Hole Under Static Compressive Loading", ASME Trans. J. Eng. Materials and Tech., accepted to appear.

5. Lekhnitskii, S., 1963, "Theory of Elasticity of an Anisotropic Elastic Body", Holden-Day Inc..

6. Starnes, J. and Williams, J.G., 1982, "Failure Characteristics of Graphite-Epoxy Structural Components Loaded in Compression", NASA TM 84552 .

7. Rhodes, M., Mikulas, M., and McGowan, P., 1982, "Effect of Orthotropic Properties and Panel Width on the Compression Strength of Graphite-Epoxy Laminates with Holes", AIAA paper No. 82-0749.

8. Shuart, M.J. and Williams, J.G., 1986, "Compression Behavior of [+45/-45] Dominated Laminates with a Circular Hole or Impact Damage", AIAA Journal, vol. 24, No. 1, pp. 115-122.
9. Knaus, J., and Starnes, J., and Henneke, E., 1978, "The Compressive Failure of GraphiteEpoxy Plates with Circular Holes", NASA CR 157115, N78-24295.

10. Mikulas, M., 1980, "Failure Prediction Techniques for Compression Loaded Composite Laminates", NASA CP 2142.

11. Waas, A., Babcock, C.D., and Knauss, W.G., 1989, "An Experimental Study of the Initiation and Progression of Damage in Compressively Loaded Composite Laminates in the Presence of a Circular Cutout", AIAA paper 89-1274-CP.

12. Waas, A., Babcock, C.D., and Knauss, W.G., 1990, "An Experimental Study of the Compression Failure of Fibrous Laminated Composites in the Presence of Stress Gradients", International Journal of Solids and Structures, Vol. 26, No. 9/10, pp. 1071-1098.

13. Soutis, C., and Fleck, N.A., 1990, "Static Compression Failure of Carbon Fibre 'T800/924C Composite Plate with a Single Hole", Journal of Composite Materials, Vol. 24, pp. 536-558.

14. El-Zein, M. S., and Reifsneider, K.L., 1990, "The Strength Prediction of Composite Laminates Containing a Circular Hole", Journal of Composites Technology \& Research, JCTRER, Vol. 12, No. 1, pp. 24-30.

15. Guynn, E. G., and Bradley, W. L., 1989, "A Detailed Investigation of the Micromechanisms of Compressive Failure in Open Hole Composite Laminates", Journal of Composite Materials, vol.23, May, pp. 479-504.

16. Sohi, M.M., Hahn, H.T., and Williams, J.G., 1987, "The Effect of Resin Toughness and Modulus on Compressive Failure Modes of Quasi-Isotropic Graphite/Epoxy Laminates", Toughened Composites, ASTM STP 937, pp. 37-60.

17. Lessard, L., B., and Chang, F., 1991, "Damage Tolerance of Laminated Composites Containing an Open Hole and Subjected to Compressive Loadings: Part II-Experiment", Journal of Composite Materials, Vol. 25, January, pp. 44-64.

18. Waas, A., 1988, "Compression Failure of Fibrous Laminated Composites in the Presence of Stress Gradients: Experiment and Analysis", Ph.D. thesis, California Institute of Technology.

19. Tsai, S.W., and Hahn, H.T., 1980, "Introduction to Composite Materials", Technomic Publishing Company, Connecticut. 
Table 1 Graphite, Epoxy and Thermoplastic Properties

\begin{tabular}{||c|c|c|c|c||}
\hline \hline Material & $\begin{array}{c}E \\
(\mathrm{ksi})\end{array}$ & $\nu$ & $\begin{array}{c}G \\
(\mathrm{ksi})\end{array}$ & $\begin{array}{c}\text { Thickness } \\
(\text { inch) }\end{array}$ \\
\hline \hline $\begin{array}{c}\text { Polyetherinicle } \\
\text { (ULTEM) } \\
\text { F } 155\end{array}$ & $480^{a}$ & $0.38^{b}$ & $174^{c}$ & $0.1335^{d}$ \\
$\begin{array}{c}\text { (Epoxy) } \\
\text { G30-500 } \\
\text { (BASF Celion Fiber) }\end{array}$ & $470^{e}$ & $0.34^{b}$ & $175^{c}$ & \\
\hline \hline
\end{tabular}

${ }^{a} \mathrm{GE}$ Plastics Data Sheet

${ }^{b}$ See Ref 2

${ }^{c} G=\frac{E}{2(1+\nu)}$ for isotropic material

${ }^{d}$ measured experimentally

¿Hexcel Corp. Data Sheet

t Hexcel Corp. Data Sheet and verified optically
Table 2 Laminate Material Properties

\begin{tabular}{||c|c|c|c|c||}
\hline \hline & $\begin{array}{c}E_{11} \\
(\mathrm{ksi})\end{array}$ & $\begin{array}{c}E_{22} \\
(\mathrm{ksi})\end{array}$ & $\nu_{12}$ & $\begin{array}{c}G_{12} \\
(\mathrm{ksi})\end{array}$ \\
\hline \hline Experiment & 904.288 & 574.573 & 0.362 & $a$ \\
Theory $^{b}$ & 1017.837 & 548.566 & 0.374 & 186.684 \\
\hline
\end{tabular}

${ }^{a}$ No experimental data available

${ }^{b}$ using Modified ROM, see ref. 19

\begin{tabular}{|c|c|c|c|c|}
\hline Specimen & $\begin{array}{l}\text { Hole Size } \\
(d / w)^{a}\end{array}$ & $\begin{array}{c}\text { Far Field Failure } \\
\text { stress (psi) }\end{array}$ & $\begin{array}{c}\text { Failure Strain at } \\
\text { the Hole }{ }^{b}(\mu \text { strain })\end{array}$ & Type of Failure \\
\hline 1 & 0.005 & 6385 & 28000 & crack at bottom free edge. $\mathrm{TS}^{c}$ \\
\hline 2 & 0.005 & 7511 & 33700 & $\mathrm{CSF}^{d}$ \\
\hline 3 & 0.008 & 5152 & 20200 & crack at top free edge. TS \\
\hline 4 & 0.008 & 5364 & 19400 & crack at bottom free edge. TS \\
\hline 5 & 0.008 & 8571 & 37900 & CSF \\
\hline 6 & 0.017 & 8245 & 30145 & CSF \\
\hline 7 & 0.017 & 8745 & 36400 & CSF \\
\hline 8 & 0.017 & 8136 & 33664 & CSF \\
\hline 9 & 0.028 & 6907 & 28121 & CSF \\
\hline 10 & 0.028 & 8030 & 30400 & CSF \\
\hline 11 & 0.028 & 9132 & 38381 & CSF \\
\hline 12 & 0.045 & 6695 & 18755 & CSF \\
\hline 13 & 0.045 & 6015 & 20710 & $\mathrm{CSF}$ \\
\hline 14 & 0.062 & 6182 & 19443 & $\begin{array}{l}\text { crack at top of hole } \\
\text { followed by CSF }\end{array}$ \\
\hline 15 & 0.062 & 6987 & 23800 & $\mathrm{CSF}$ \\
\hline 16 & 0.062 & 8398 & 26666 & crack at top of hole. TS \\
\hline 17 & 0.071 & 5100 & 17522 & $\begin{array}{l}\text { crack and delamination } \\
\text { at top of hole. TS }\end{array}$ \\
\hline 18 & 0.071 & 5279 & 16821 & $\begin{array}{c}\text { crack and delamination } \\
\text { at top of hole. TS }\end{array}$ \\
\hline 19 & 0.086 & 6680 & 21929 & $\begin{array}{l}\text { crack and delamination } \\
\text { at top of hole. CSF }\end{array}$ \\
\hline 20 & 0.086 & 6203 & 20254 & $\begin{array}{c}\text { crack and delamination } \\
\text { at top of hole. TS }\end{array}$ \\
\hline 21 & 0.103 & 5335 & 17362 & crack at top of hole. TS \\
\hline 22 & 0.103 & 4294 & 14298 & $\begin{array}{l}\text { crack and delamination at } \\
\text { top and bottom of hole. TS }\end{array}$ \\
\hline
\end{tabular}

Table 3 Test Specimens, Hole Sizes, Failure Stresses, Failure Strains and Type of Failure (to be continued) 


\begin{tabular}{|c|c|c|c|c|}
\hline Specimen & $\begin{array}{l}\text { Hole Size } \\
(d / w)^{a}\end{array}$ & $\begin{array}{c}\text { Far Field Failure } \\
\text { stress (psi) }\end{array}$ & $\begin{array}{l}\text { Failure Strain at } \\
\text { the Hole } \text { Hostrain })^{b}\end{array}$ & Type of Failure \\
\hline 23 & 0.103 & 4855 & 15319 & $\begin{array}{l}\text { crack and delamination at } \\
\text { top and bottom of hole. TS }\end{array}$ \\
\hline 24 & 0.124 & 5890 & 19270 & $\begin{array}{l}\text { crack and delamination at } \\
\text { top and bottom of hole. TS }\end{array}$ \\
\hline 25 & 0.124 & 5942 & 20826 & $\begin{array}{l}\text { crack and delamination at } \\
\text { top and bottom of hole. TS }\end{array}$ \\
\hline 26 & 0.124 & 6814 & 24072 & $\begin{array}{l}\text { crack and delamination at } \\
\text { top and bottom of hole. TS }\end{array}$ \\
\hline 27 & 0.144 & 4130 & $-^{e}$ & $\begin{array}{l}\text { crack and delamination at } \\
\text { top and bottom of hole. TS }\end{array}$ \\
\hline 28 & 0.144 & 3887 & - & $\begin{array}{c}\text { crack and delamination } \\
\text { at top of hole. TS }\end{array}$ \\
\hline 29 & 0.144 & 4476 & 12179 & $\begin{array}{l}\text { crack and delamination } \\
\text { at top of hole. TS }\end{array}$ \\
\hline 30 & 0.144 & 4643 & 13540 & $\begin{array}{l}\text { crack and delamination } \\
\text { at bottom of hole. } \text { CSF }^{d}\end{array}$ \\
\hline 31 & 0.167 & 3435 & 11930 & $\begin{array}{l}\text { crack and delamination } \\
\text { at bottom of hole. TS }\end{array}$ \\
\hline 32 & 0.167 & 3602 & 11784 & $\begin{array}{l}\text { crack and delamination at } \\
\text { top and bottom of hole. TS }\end{array}$ \\
\hline 33 & 0.167 & 4727 & 16728 & $\begin{array}{l}\text { crack and delamination } \\
\text { at top of hole. TS }\end{array}$ \\
\hline 34 & 0.198 & 2790 & 11000 & $\begin{array}{l}\text { crack and delamination at } \\
\text { top and bottom of hole. TS }\end{array}$ \\
\hline 35 & 0.198 & 4948 & 20863 & $\begin{array}{l}\text { crack and delamination at } \\
\text { top and bottom of hole. TS }\end{array}$ \\
\hline 36 & 0.198 & 3331 & 13049 & $\begin{array}{l}\text { crack and delamination at } \\
\text { top and bottom of hole. TS }\end{array}$ \\
\hline 37 & 0.198 & 4182 & 16146 & $\begin{array}{c}\text { crack and delamination at } \\
\text { bottom of hole. TS }\end{array}$ \\
\hline
\end{tabular}

Table 3 Test Specimens, Hole Sizes, Failure Stresses, Failure Strains and Type of Failure

Table 4 Buckling Analysis for Failure at the Hole

\begin{tabular}{|c|c|c|c|c|c|}
\hline Specimen & $\begin{array}{c}\text { Hole Sizo } \\
(d / w)^{n}\end{array}$ & $\begin{array}{l}\text { Inplane } \\
\left(\lambda / d_{f}\right)^{6}\end{array}$ & \# Bands & $\begin{array}{c}\text { Out of plane } \\
\left(\lambda / d_{f}\right)\end{array}$ & \# Bands \\
\hline 10 & 0.002 & 20.5 & 1 & $5.00^{c}, 0.2,7,8,8.3$ & 4 \\
\hline 17 & 0.071 & 21.0 & 1 & $3.3,10.0,10.0$ & 3 \\
\hline 10 & 0.080 & 21.0 & 1 & $5.4,9.2$ & 2 \\
\hline 22 & 0.103 & 24.5 & 1 & $3.3,6.5$ & 2 \\
\hline 2.4 & 0.124 & 24.5 & 1 & $3.1,6.8$ & 2 \\
\hline 20 & 0.141 & 20.0 & 1 & $\underline{3.8}, 0 . \overline{4}, 8.5$ & 3 \\
\hline 32 & 0.107 & 23.0 & 1 & $4.6,7.2$ & 2 \\
\hline 37 & 0.108 & 22.0 & 1 & 6.0 & 1 \\
\hline
\end{tabular}

${ }^{a} \mathrm{~d}$ =hole diameter, $w=$ plate width

${ }^{b} \lambda$ is the buckled half wavelength and $d_{f}$ is the fiber diameter

ckink pattern common to all specimens is underlined
Table 5 Comparison of FEA and Experimental results for Buckling Load and Mode Estimates for Plates with Hole Sizes in the Range for Failure Initiation at the Hole Edge

\begin{tabular}{|c|c|c|c|c|}
\hline \hline Hole Sizc & $\begin{array}{c}\lambda^{0} \\
\text { (FEA) }\end{array}$ & $\begin{array}{c}\lambda^{c} \\
\text { (Experincht) }\end{array}$ & $\begin{array}{c}\text { Wavelength } \\
\text { (FEA) }\end{array}$ & $\begin{array}{c}\text { Wavelength } \\
\text { (Exporincut) }\end{array}$ \\
\hline \hline 0.062 & 10050 & $6000-7000$ & 0.063 & 0.056 \\
0.086 & 9088 & $5500-6500$ & 0.048 & 0.010 \\
0.124 & 8240 & $5000-6000$ & 0.036 & 0.033 \\
0.198 & 7434 & $3000-5000$ & 0.023 & 0.018 \\
\hline
\end{tabular}

${ }^{a}$ Hole Diameter/Plate Width aspect ratio

${ }^{b}$ Eigenvalue corresponding to the Far Field Buckling Stress (psi)

'For Exp. results, a range of Far Field Buckling Stresses is given (psi)

${ }^{d}$ buckled half wavelength divided by the hole diameter 


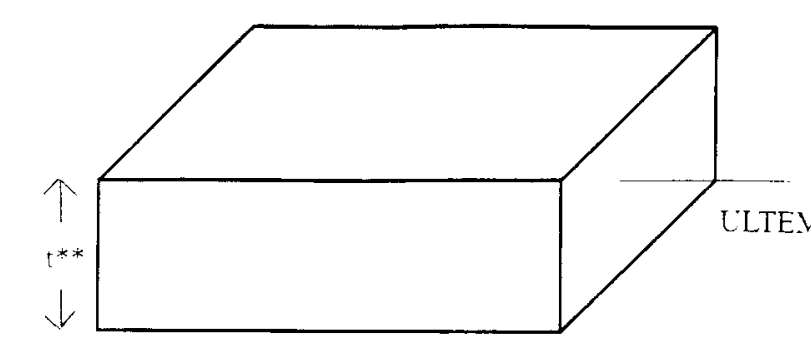

fiber orientation in ply

GR/EP UNIPLY
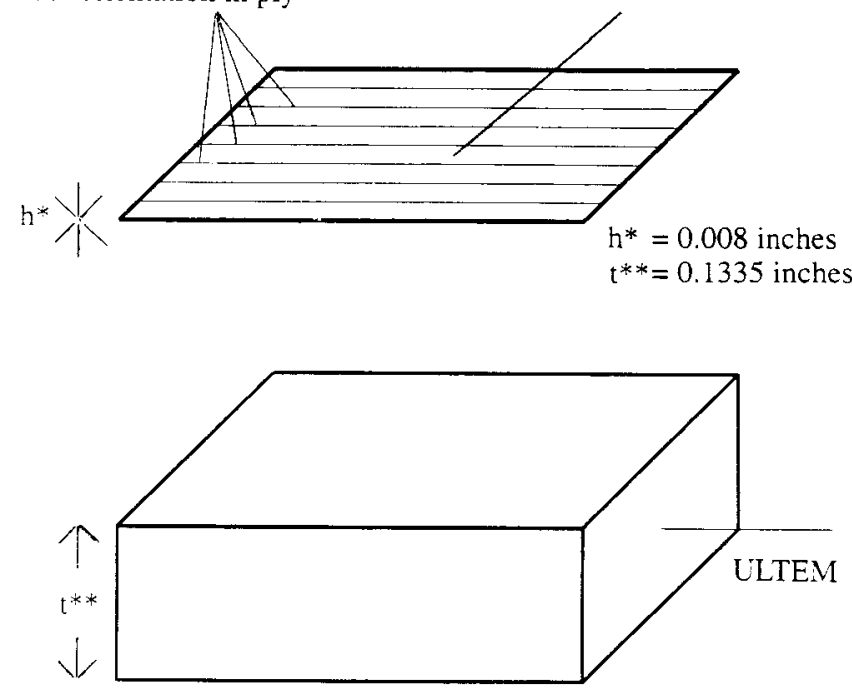

Fig. 1 Laminate Stacking Sequence

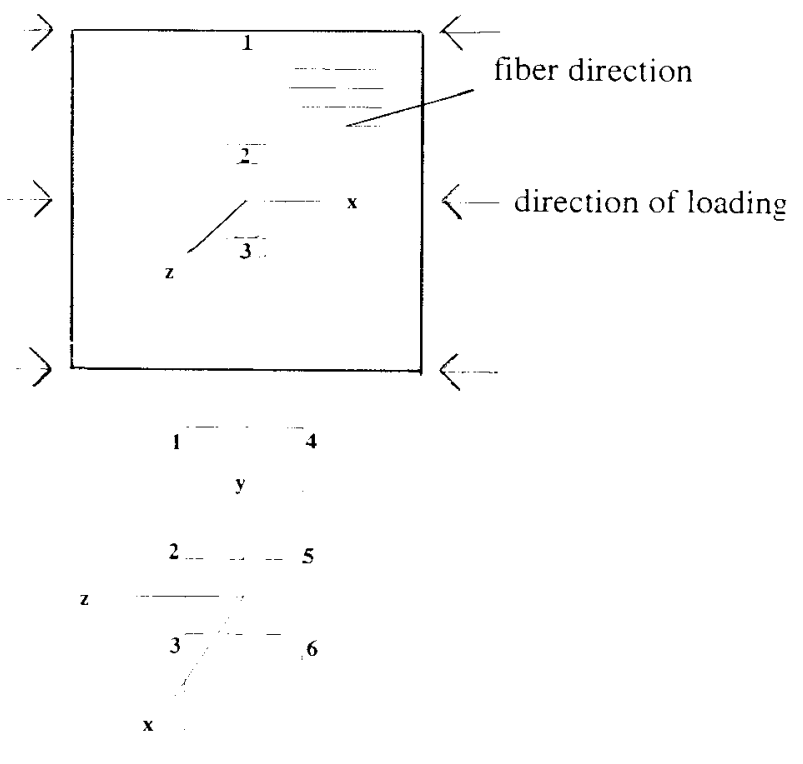

Fig. 2 Location of Strain Gages on Test Specimens

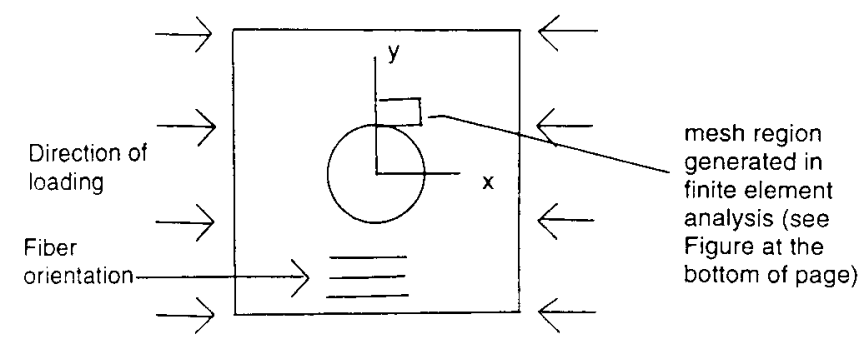

Top View of the mid-ply, see diagram below, showing the loading direction, fiber direction, and the region which was meshed in the finite element analysis

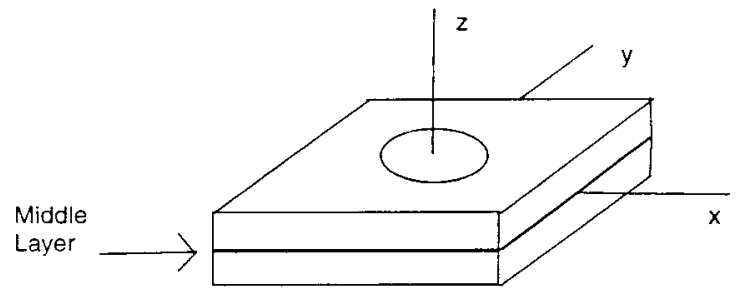

Side View of Uniply composite plate ( Note: The middle layer, consisting of the graphite/epoxy tape, is shown in the above diagram)

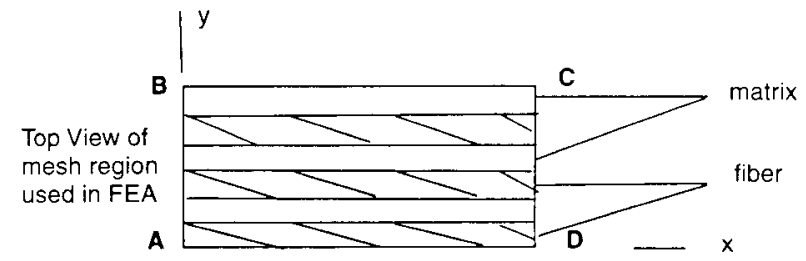

Fig. 3 FEM Mesh Location on the Plate Specimen

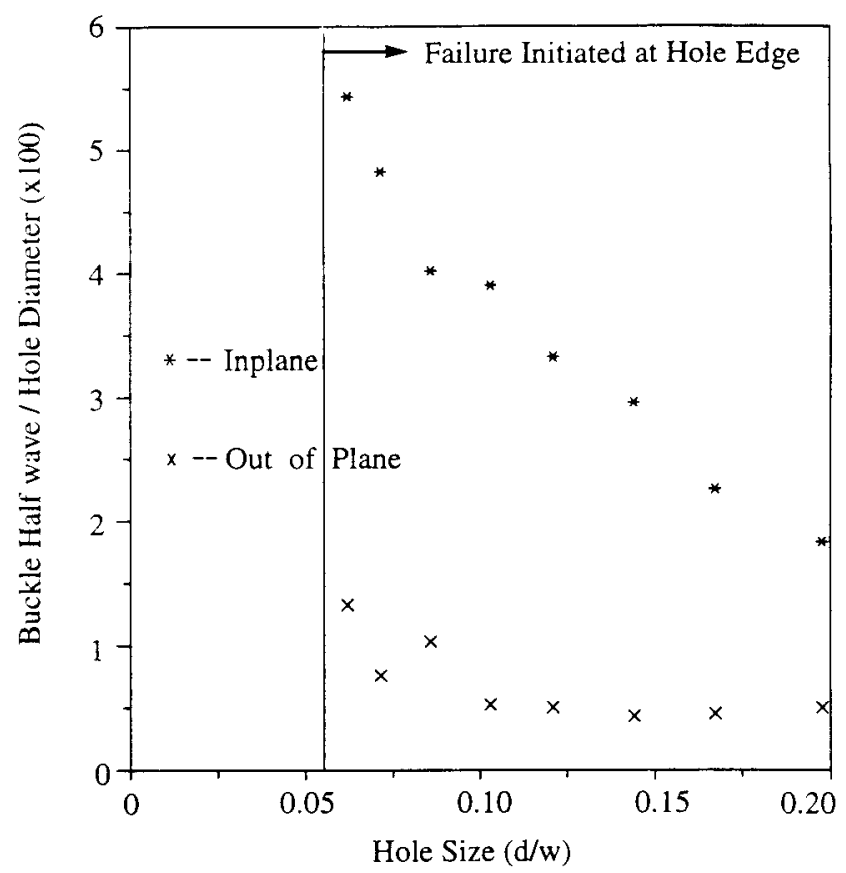

Fig. 5 Inplane / Out of Plane Buckling Wavelength vs. Hole Size 

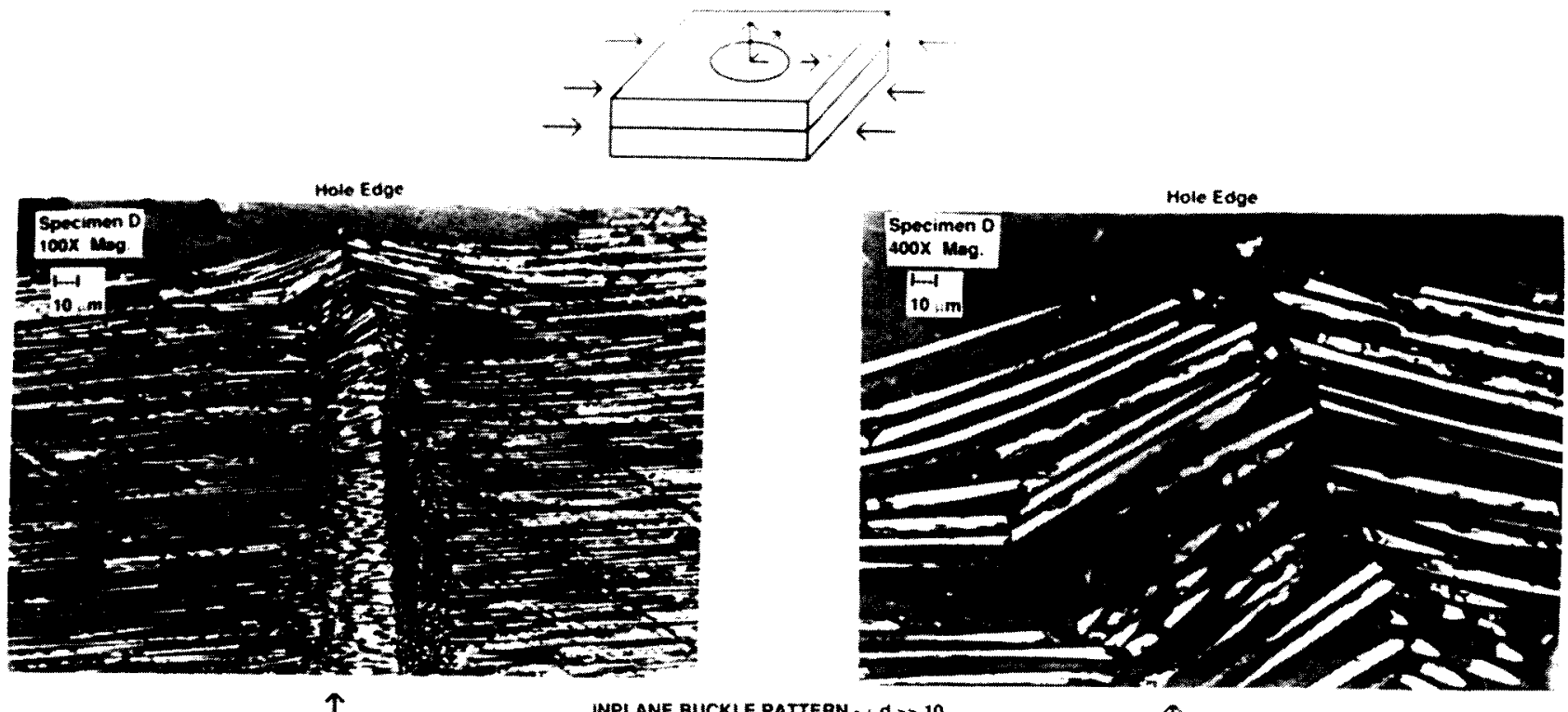

INPLANE BUCKLE PATTERN , d $d>10$ VIEW: XY PLANE

OUT OF PLANE BUCKLE PATTEAN VIEW $X Z$ PLARE $\quad 0 * 10$

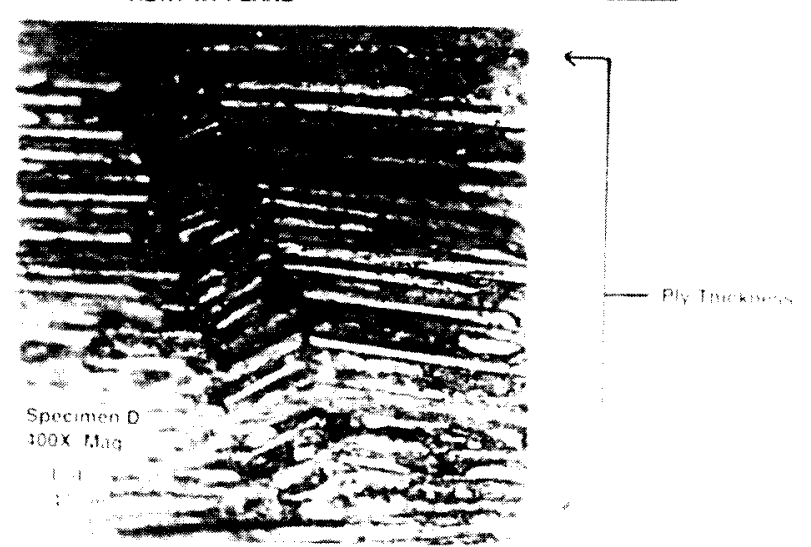

Fig. 4 Inplane/Out of Plane Buckling for Specimen 37

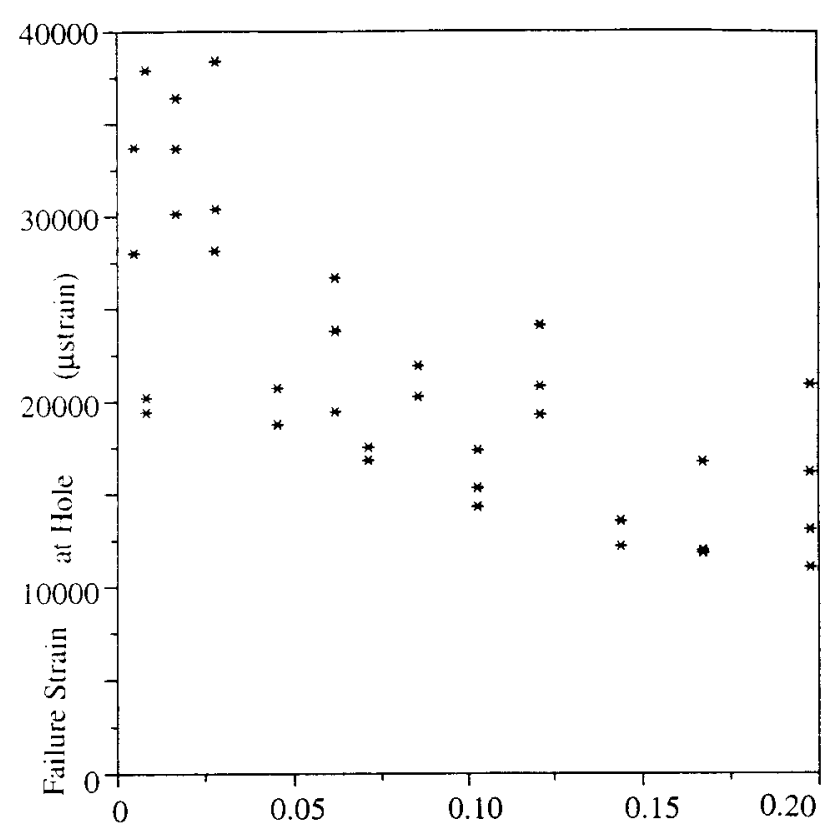

Hole Size $(\mathrm{d} / \mathrm{w})$

Fig. 6 Plot of Failure strain (at the hole edge) vs. Hole Aspect Ratio

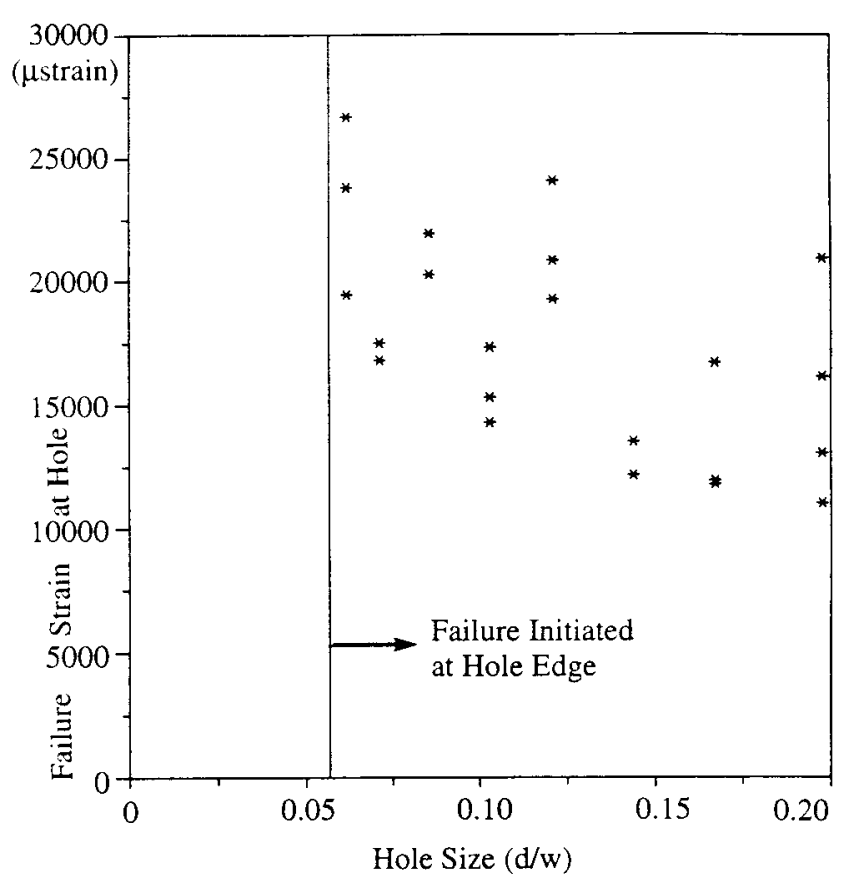

Fig. 7 Plot of Failure strain (at the hole edge) vs. Hole Aspect Ratio for Failure Initiation at the Hole 


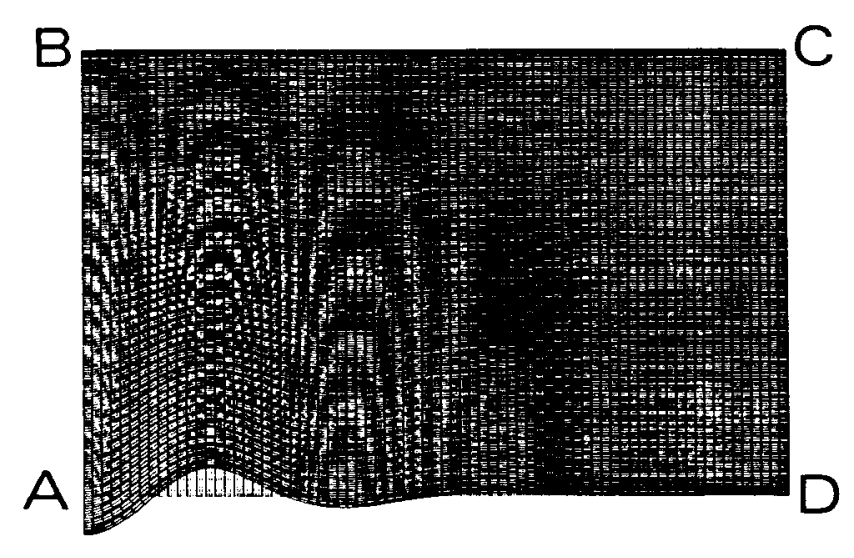

Fig. 8 FEM Mesh of Symmetric Mode (Buckling) for Plate with 0.12 Hole Aspect Ratio

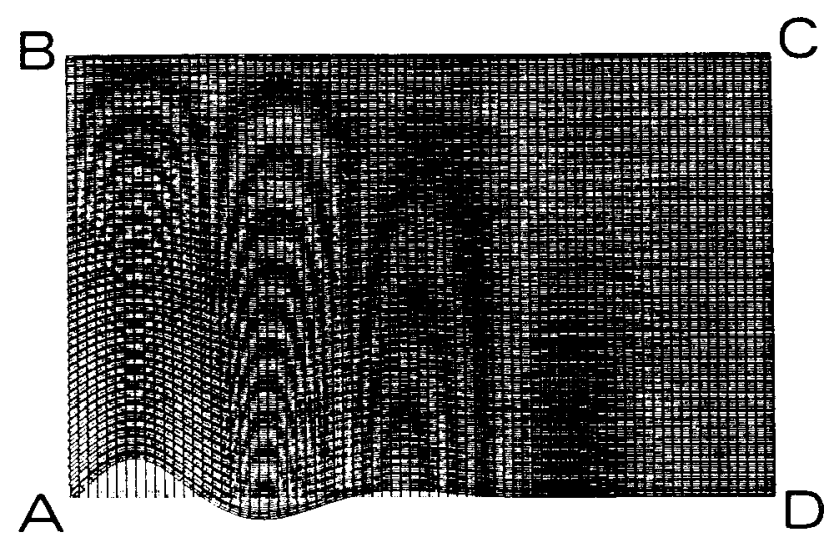

Fig. 9 FEM Mesh of Antisymmetric Mode for Plate with 0.12 Hole Aspect Ratio 